\title{
Методика настройки микросканера на базе плоскопараллельной пластинки
}

\author{
И.И. Кремис, Р.А. Гладков \\ Филиал ИФП СО РАН «КТИПМ», Новосибирск, 630090, просп. Лаврентьева, 2/1 \\ тел: (383) 330-91-06, эл. почта: igor21738@ngs.ru
}

DOI 10.34077/RCSP2019-175

Потенциальные возможности тепловизионной техники в паре со сканирующим устройством, представляют не малый интерес, учитывая преимущества, которые добавляются при наблюдении за внешним объектом. Преимущества, с использованием микросканера (MC), подробно описаны в статье [1]. МС на базе плоскопараллельной пластинки позволяет эффективно отклонять проекцию сцены в плоскости матрицы фотоприёмника, но гарантировано отклонить поток на заданное расстояние представляет не простую задачу. Также, учитывая необходимость оперативной юстировки приборов в лабораторных условиях (в составе системы назначения) и нахождение ИК излучения в невидимом глазу части спектра, возникла необходимость в разработке простых методов решающих такую задачу.

Основой метода является перевод измерений из области инфракрасного диапазона спектра в видимый. Все вычисления проводятся в отражённом свете с использованием необходимых параметров пластинки. Критичным параметром является клиновидность - паразитная составляющая для плоскопараллельной пластинки. Определение угла клиновидности, с использованием доступных материалов и приборов, будет рассмотрено отдельно.

В утилитарных целях необходимо определить угол падения внешней сцены на пластинку микросканера. На схеме рис.1 луч лазера, проходя отверстие в экране, отражается от германиевой пластинки 3 и падает на экран в точке А. С использованием теоремы тангенса, определяется угол падения сцены $\alpha$.

В распоряжении все необходимые данные: толщина пластинки d; расстояние от пластинки 3 до матрицы 1; угол клиновидности $\theta$ пластинки; показатель преломления пластинки n; угол падения сцены на пластинку. Формула, для определения

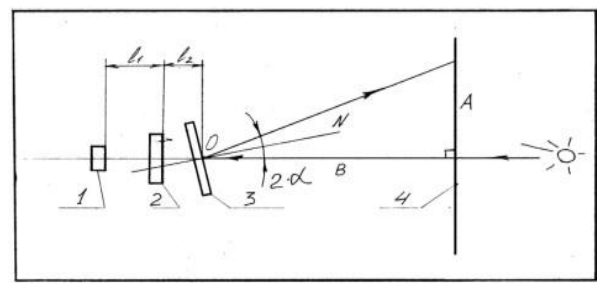
смещения проекции изображения $\mathrm{L}$ в плоскости матрицы, выводится из оптической схемы рис.2. B общем виде:

Рис.1.

$$
\mathrm{L}=\mathrm{L}_{1}+\mathrm{L}_{2}
$$

Где L1=DZ смещение, вносимое идеальной плоскопараллельной пластинкой. Смещение, создаваемое оптическим клином с углом $\theta$ :

$\mathrm{L} 2=\operatorname{tg}\left(\alpha_{1}-\varphi-\arcsin \left(\frac{\mathrm{n}_{2}}{\mathrm{n}_{1}} \sin \left(\beta_{1}-\varphi\right)\right)\right) * \mathrm{BZ}$. .На последнем этапе в настройке $\mathrm{MC}$ на базе плоскопараллельной пластинки необходимо убедиться, что путь, смещения проекции сцены, формирует условный квадрат, стороны которого лежат строго вертикально и горизонтально. Для этого в микросканер введён синхронизатор, который включает диодный лазер только в момент прохождения углов квадрата лазерным пучком. Таким образом, на экране рис. 1 визуально будет виден квадрат, который пропорционально “ложиться” на матрицу приёмника со сторонами, определяемыми по (1). Проведённые эксперименты с настройкой МС подтвердили работоспособность методики.

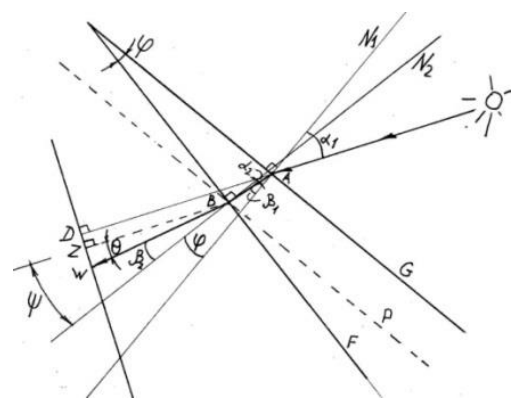

Рис. 2.

\section{Лuтература}

[1] Кремис И.И, Толмачев Д.А. Гладков// Фильтрация остаточной неоднородности и дефектов изображения в тепловизорах третьего поколения с использованием микро сканирования. Прикладная физика № 1. 2017. 